\title{
The programmable valve of a ventriculoperitoneal shunt for hydrocephalus
}

\author{
Marcelo Moraes Valença ${ }^{1}$ (D) Ana Cristina Veiga da Silva ${ }^{1}$ (D) Luiz Severo Bem Junior ${ }^{1}$ (D), \\ Elayne Cristina de Oliveira Ribeiro' ${ }^{1 D}$, Marcelo Andrade Valença ${ }^{1}$ (D), \\ Alberto Henrique Torres Trindade da Silva ${ }^{2}$ (D), Déborah Emmily de Carvalho ${ }^{2}$ (D), \\ Martina Falcão Valença ${ }^{3}$ iD
}

${ }^{1}$ Universidade Federal de Pernambuco, Recife, Pernambuco, Brazil

${ }^{2}$ Universidade de Pernambuco, Recife, Pernambuco, Brazil

${ }^{3}$ Städtisches Klinikum Dresden, Dresden, Germany

$凶$

Marcelo Moraes Valença mmvalenca@yahoo.com.br

Edited by:

Juliana Ramos de Andrade
Figure 1 (front cover of this edition) shows a 3-D reconstruction of a computed tomography (CT) scan of the skull of a patient who developed normal pressure hydrocephalus months after severe traumatic brain injury. ${ }^{1}$ A programmable valve $^{2}$ was implanted as part of a right posterior parietal ventriculoperitoneal shunt using the Keen's point ( $3 \mathrm{~cm}$ posterior, $3 \mathrm{~cm}$ superior to the ear's pinna). ${ }^{3}$

On a ventriculoperitoneal shunt, the cerebrospinal fluid (CSF) flow is, due to the valve, unidirectional, and the CSF is drained from the lateral ventricle to the peritoneum. In Figure 1 the ventricular catheter can be seen exiting the valve towards the posterior parietal burr hole. The peritoneal catheter is attached to the most distal part of the valve and heads downwards, in subcutaneous tissue, towards the abdomen.

In Figure 2, a sagittal and a transversal views of a skull CT shows the lateral fissure and superior temporal sulcus, as well as the localization where the ventricular catheter penetrates the cerebral cortex.

Types of valves can also be subdivided into valve feature, non-gravitational, gravitational, non-programmable, programmable and can be subdivided into non-gravitational non-programmable, non-gravitational programmable, gravitational non-programmable and gravitational programmable. ${ }^{4}$ The gravitational ones have more mechanical failures than the non-gravitational ones, the same conclusion was observed for the programmable when compared to the non-programmable ones. ${ }^{4}$ In patients with hydrocephalus the most used modalities are ventriculoperitoneal and ventriculoatrial. ${ }^{5,6}$

Advances in bioengineering led to the development of programmable valves; ${ }^{7.9}$ it is possible to determine the valve opening pressure so that the CSF passes through the valve and permit adequate drainage, relieving intracranial hypertension or decreasing the volume of the cerebral ventricles. ${ }^{10}$ 
The great advantage of this type of valve is that the pressure can be changed or adjusted by placing a device outside the skin over the valve. It is painless and non-invasive and can be done in the doctor's office. Thus, insufficient CSF drainage or excessive fluid oufflow from the ventricles, the later a possible cause of iatrogenic chronic subdural hematoma, ${ }^{11,12}$ can be carefully regulated.
Programmable shunts also need lower revisions, therefore are more cost-effective and can provide better neurological outcomes than non-programmable shunts by reducing drainage problems. ${ }^{13}$

The patient and his wife authorized the publication of the images in this article.
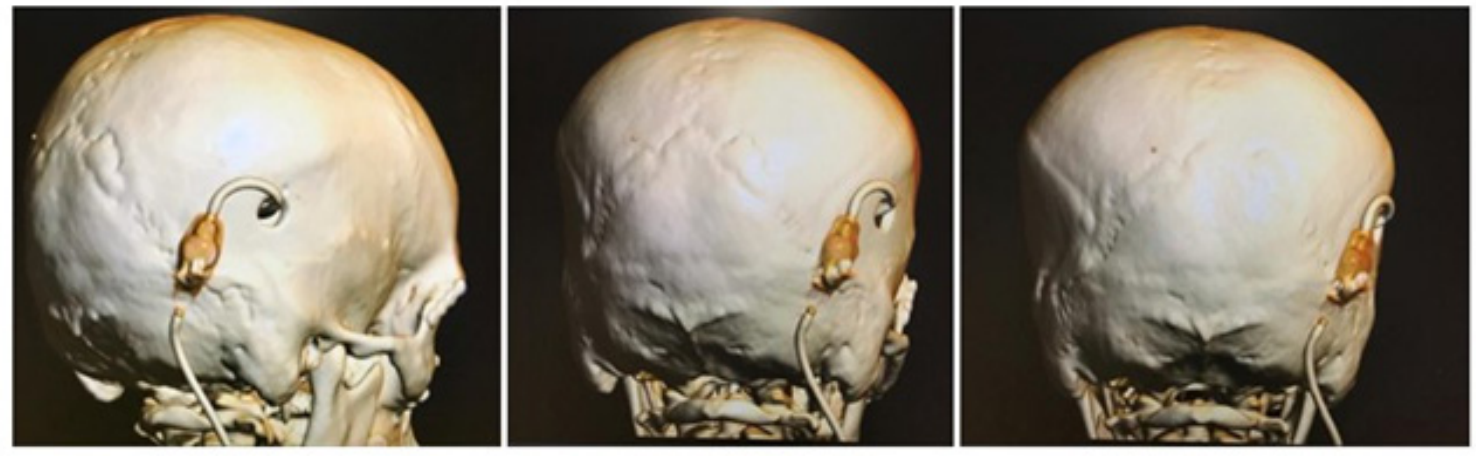

Figure 1. 3-D reconstruction of a CT scan of the skull in a patient who developed normal pressure hydrocephalus months after severe traumatic brain injury. A programmable valve was implanted as part of a right posterior parietal ventriculoperitoneal shunt using Keen's point.

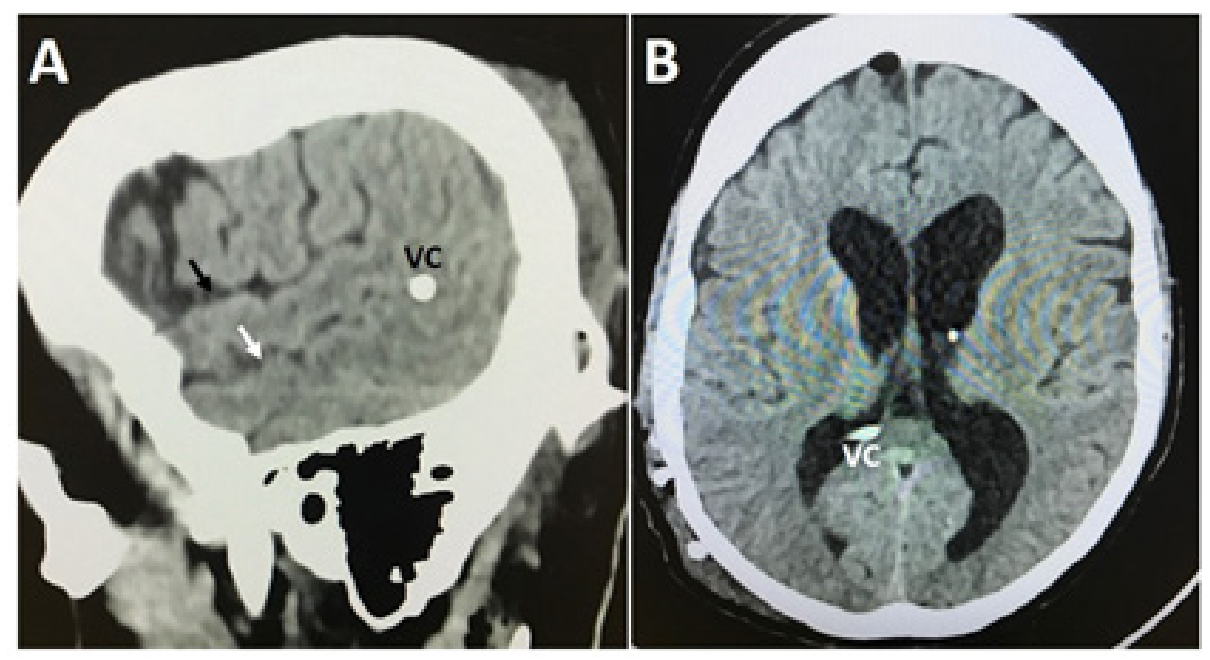

Figure 2. A. Right lateral sagittal view of a skull CT; black arrow, lateral fissure; white arrow, superior temporal sulcus. A: VC, ventricular catheter; B. Transverse CT view of the skull; VC - end of ventricular catheter. 
Author's contribution: the authors contributed the similar form.

Marcelo Moraes Valença

https://orcid.org/0000-0003-0678-3782

Ana Cristina Veiga Silva

https://orcid.org/0000-0002-1149-4427

Luiz Severo Bem Junior

https://orcid.org/0000-0002-0835-5995

Elayne Cristina de Oliveira Ribeiro

https://orcid.org/0000-0002-5243-3356

Marcelo Andrade Valença

https://orcid.org/0000-0002-0824-0928

Alberto Henrique Torres Trindade da Silva

https://orcid.org/0000-0003-2356-4426

Déborah Emmily de Carvalho

https://orcid.org/0000-0002-8068-3598

Martina Falcão Valença

https://orcid.org/0000-0002-4085-3118

\section{References}

1. Sahuquillo J, Rosas K, Calvo H, Alcina A, Gándara $D$, López-Bermeo D and Poca MA. How to Choose a Shunt for Patients with Normal Pressure Hydrocephalus: A Short Guide to Selecting the Best Shunt Assembly. J Clin Med 2021;10(6):1210 Doi: $10.3390 / \mathrm{jcm} 10061210$

2. Tey ML, Ng LP, Low DCY, Seow WT and Low SYY. Programmable Shunt Valves for Pediatric Hydrocephalus:22-YearExperiencefromaSingapore Children's Hospital. Brain Sci 2021;11(11):1548 Doi:10.3390/brainsci 11111548

3. Morone PJ, Dewan MC, Zuckerman SL, Tubbs RS and Singer RJ. Craniometrics and Ventricular Access: A Review of Kocher's, Kaufman's, Paine's, Menovksy's, Tubbs', Keen's, Frazier's, Dandy's, and Sanchez's Points. Oper Neurosurg (Hagerstown) 2020;18(5):461-469 Doi:10.1093/ons/opz 194

4. Hall BJ, Gillespie CS, Sunderland GJ, Conroy EJ, Hennigan $D$, Jenkinson MD, . . Mallucci C. Infant hydrocephalus: what valve first? Childs Nerv Syst 2021;37(1 1):3485-3495 Doi:10.1007/s00381021-05326-1

5. Popal AM, Zhu Z, Guo X, Zheng Z, Cai C, Jiang $\mathrm{H}$, . . . Zhu J. Outcomes of Ventriculoperitoneal Shunt in Patients With Idiopathic Normal-Pressure Hydrocephalus 2 Years After Surgery. Front Surg 2021;8:641561 Doi:10.3389/fsurg.2021.641561
6. Niu H, Wu H, Luo W, Wang K, Zhao L and Wang $Y$. Ventriculoatrial shunt as a feasible regimen for certain patients of hydrocephalus: clinical features and surgical management. Acta Neurol Belg 2021;121(2):403-408 Doi:10.1007/s13760. 019-01180-w

7. Aghayev K, lqbal SM, Asghar W, Shahmurzada $B$ and Vrionis FD. Advances in CSF shunt devices and their assessment for the treatment of hydrocephalus. Expert Rev Med Devices 2021;18(9):865-873 Doi:10.1080/17434440. 2021.1962289

8. Berns J, Priddy B, Belal A, Seibold RD, Zieles K and Jea A. Standardization of cerebrospinal fluid shunt valves in pediatric hydrocephalus: an analysis of cost, operative time, length of stay, and shunt failure. J Neurosurg Pediatr 2021;27(4):400-405 Doi: 10.3171/2020.8.Peds20477

9. Mitchell KS, Zelko I, Shay T, Horen S, Williams A, Luciano $M, \ldots$ Gordon CR. The Impact of Hydrocephalus Shunt Devices on Quality of Life. J Craniofac Surg 2021;32(5):1746-1750 Doi:10.1097/scs.0000000000007579

10. Talbot-Stetsko HK, Rave KD, Aaron BL, Adapa AR, Altshuler DB, Srinivasan S, . . . Khalsa SSS. Ventricular Volume Change as a Predictor of Shunt-Dependent Hydrocephalus in Aneurysmal Subarachnoid Hemorrhage. World Neurosurg 2022;157:e57-e65 Doi:10.1016/i. wneu.2021.09.085

11. Lodhia J, Rashid SM, Msemo A, Philemon R, Sadiq $A$, Chilonga $K$ and Msuya D. Bilateral Subdural Hematoma following Ventriculoperitoneal Shunt Insertion in a Ten-month Old Tanzanian Female with Congenital Hydrocephalus: An Uncommon Presentation. East Afr Health Res J 2021;5(1):1719 Doi:10.24248/eahri.v5i1.646

12. Feletti $A$, d'Avella D, Wikkelsø C, Klinge P, Hellström $P$, Tans J, . . L Laurell K. Ventriculoperitoneal Shunt Complications in the European Idiopathic Normal Pressure Hydrocephalus Multicenter Study. Oper Neurosurg (Hagerstown) 2019;17(1):97-102 Doi:10.1093/ons/opy232

13. Lee L, King NK, Kumar D, Ng YP, Rao J, Ng H, ... Ng I. Use of programmable versus nonprogrammable shunts in the management of hydrocephalus secondary to aneurysmal subarachnoid hemorrhage: a retrospective study with costbenefit analysis. J Neurosurg 2014;121(4):899. 903 Doi: $10.3171 / 2014.3 . J n s 131088$ 